\title{
Body Mass Index in Children with Psoriasis
}

\section{Murzina E*}

Department of Dermatovenereology, Shupyk National Medical Academy of Postgraduate Education, Ukraine

*Corresponding author: Elvina Murzina, Department of Dermatovenereology, Shupyk National Medical Academy of Postgraduate Education, Kostiantynivska Street, apt.3, Kyiv, 04071, Ukraine, Tel: +380677355756; Email: elvina2003@ukr.net

\section{Research article}

Volume 5 Issue 1

Received Date: February 28, 2020

Published Date: March 20, 2020

DOI: $10.23880 /$ cdoaj-16000207

\section{Abstract}

Psoriasis in children can be caused or even exacerbated by emotional stress, $\beta$-hemolytic streptococcal infection of the pharynx and perianal region, Kawasaki's disease, withdrawal of systemic corticosteroids, increase in body mass index (BMI). The World Health Organization defines overweight and obesity as a result of ectopic fat deposition that can lead to decline in health. Nowadays dermatologists focus more on the use of BMI to study progress in the treatment of psoriasis patients as obesity is considered to be an independent risk factor for psoriasis. In this article BMI in children with psoriasis aged 4-17 is analyzed. When assessing BMI, among 188 children $60 \%$ of them (113) were identified to have normal body mass index by their age. Increased BMI was reported in 66 children (35.11\%), pre-obesity was reported in 51 children (27.13\%) and extra 13 were observed to have class I obesity and 2 children - class II. The upward deviation of the average weight ranged between several and 25-30 kilograms in certain children. On average the exceedance of upper limits of the mean weight in children with increased BMI comprised $15.49 \pm 1.53 \%$. The subnormal weight was observed in 6 children and 3 were underweight. The above-average weight and average height - the most typical combination for increased BMI - was reported in 24 children. The above-average weight and height and the above-average weight combined with the mean height were observed in 18 and 12 children respectively.

Keywords: Pediatric Psoriasis; Psoriasis Types; Body Mass Index

Abbreviations: BMI: Body Mass Index; PP: Plaque Psoriasis.

\section{Introduction}

Psoriasis is a chronic, multisystemic, inflammatory disease involving almost $1 \%$ of children. In psoriasis the interaction of multigenic predisposition and environmental factors along with the way of life provoke symptoms characterized by epidermal hyperproliferation and inflammation [1,2]. Psoriasis can develop at any age. The prevalence rises linearly: from $0.2 \%$ among 1 -year-olds to $1.2 \%$ among 18-year-olds [3-5]. Emotional stress [6-8], group A streptococcal infection of the pharynx and perianal region $[4,9,10]$, Kawasaki disease [11-13], withdrawal of systemic corticosteroids, increase in body mass index (BMI) and, though it is paradoxical, TNF inhibitors [14-16] can cause or exacerbate pediatric psoriasis. Currently, dermatologists place greater focus on using BMI for studying treatment progress in patients with psoriasis, as obesity is considered to be an independent predictor of psoriasis [17].

The World Health Organization defines overweight and 


\section{Clinical Dermatology Open Access Journal}

obesity as a result of ectopic fat deposition that can lead to decline in health. In 2016 over 1.9 billion adults (39\% of males and $40 \%$ of females) over 18 had overweight, and over 650 million (11\% of males and $15 \%$ of females) among them were obese. Over the last 40 years the number of obese people worldwide has more than tripled. According to WHO in 2016 approximately 41 million children aged under 5 and 340 million children and adolescents aged from 5 to 19 had overweight or obesity. Overweight and obesity, previously supposed to be typical for high-income countries, are now becoming more widespread in low- and middle-income countries, especially in cities.

The prevalence of overweight and obesity among children and adolescents aged between 5 and 19 also increased dramatically over the last 40 years: from $4 \%$ in 1975 to over $18 \%$ in 2016 . This increase is equally distributed among children and adolescents of both sexes: $18 \%$ of girls and $19 \%$ of boys suffered from overweight in 2016. In 1975 little less than 1\% of children and adolescents aged from 5 to 19 suffered from obesity, while in 2016 their number reached 124 million ( $6 \%$ of girls and $8 \%$ of boys) [18].

Obese people are more likely to develop a variety of severe diseases: type 2 diabetes, cardiovascular diseases, osteoarthritis, gallbladder and kidney diseases, hypertension, dyslipidemia and cancer. Basically, more people die because of overweight and obesity consequences all over the world than underweight consequences. Obese people outnumber those with underweight; such a situation can be traced in all regions except for some African territories to the south of Sahara and Asia $[19,20]$.

In order to diagnose obesity and overweight, body mass index (BMI) is used, which is weight-for-height and the most convenient criterion for assessing the rates of obesity and overweight in the population, since it is equal for both sexes and all age groups. BMI is calculated as the ratio of body weight in kilograms to squared height in meters $(\mathrm{kg} / \mathrm{m} 2)$. In accordance with WHO, overweight or obesity in adults are diagnosed in the following cases:

- BMI is higher or equals 25 - overweight.

- BMI is higher or equals 30 - obesity.

The age should be considered when calculating overweight and obesity in children. In children aged under 5 overweight and obesity are calculated as follows:

- Overweight - if weight-for-height exceeds the median value, specified in WHO Child Growth Standards by more than two standard deviations.

- Obesity - if weight-for-height exceeds the median value, specified in WHO Child Growth Standards by more than three standard deviations.
In children aged between 5 and 19 overweight and obesity are calculated as follows:

- Overweight - if BMI-for-age exceeds the median value, specified in WHO Child Growth Standards by more than one standard deviation.

- Obesity - if BMI-for-age exceeds the median value, specified in WHO Child Growth Standards by more than two standard deviations [18].

\section{Objective}

To examine BMI in children with psoriasis.

\section{Materials and Methods}

188 children with psoriasis aged from 4 to 17 who underwent inpatient treatment in Kyiv Municipal Dermatology-STI Clinic in 2017-2019. Children were divided into groups depending on the biological age grouping: group 1 or early childhood-4-7-year-olds-24 children (12.77\%), group 2 or middle childhood-8-11-year-old girls, 8-12-yearold boys -56 children (29.79\%), group 3 or adolescents-85 children (45.21\%)-12-15-year-old girls, 1316 year old boys and group 4-17-year-old boys and 16-17-year-old girls-23 children $(12.23 \%)$.

Descriptive statistics was analyzed by patients' demographic characteristics (age, sex) and psoriasis features (extent of disease, clinical forms).The control group comprised 20 children without chronic somatic, skin and sexually transmitted diseases.

\section{Results and Discussion}

The mean age of children with psoriasis was $11.89 \pm 0.25$ with the disease duration ranging between 1 month and 15 years. The girls and boys were divided equally. The average duration of the last exacerbation or manifestations was 11.45 \pm 1.05 months. The extensive process was observed in 150 children, among whom plaque psoriasis (PP) prevailed-110 children. Guttate psoriasis was found in 34 (18.28\%) children. The localized process, affecting only the scalp, was found in $26(13.83 \%)$ of 188 children, in 3 children palms and feet (PPP) were affected by the psoriatic process. Nail pitting, deformity or thinning of the nail plate was observed in one quarter of children $(25.71 \%)$.

When assessing body mass index (BMI), $60 \%$ of children (113) were identified to have normal body mass index. Increased BMI was reported in 66 children (35.11\%). Among children having normal body mass index, in accordance with the age 107 children were of the mean weight and extra 7less than the average. The weight greater than the average for the corresponding age was observed in 71 children and extreme overweight in 3. Pre-obesity was reported in 51 


\section{Clinical Dermatology Open Access Journal}

children (27.13\%) and extra 13 were observed to have class I obesity and 2 children - class II. The upward deviation of the average weight ranged between several and 25-30 kilograms in certain children. On average the exceedance of upper limits of the mean weight in children with increased BMI comprised $15.49 \pm 1.53 \%$. The subnormal weight was observed in 6 children and 3 were underweight. Three-quarters of children with psoriasis from group 1 were of normal BMI, only 6 had increased BMI. Group 2 comprised the highest number of children with increased BMI $-41.06 \%$, then up to group 4 the gradual decrease in the number of children with increased BMI takes place, from $37.65 \%$ in group 3 to $21.73 \%$ in group 4 (Table 1).

\begin{tabular}{|c|c|c|c|c|c|c|c|c|}
\hline \multirow[t]{2}{*}{ BMI } & \multicolumn{2}{|c|}{$\begin{array}{c}\text { Group } 1 \\
(n=24)\end{array}$} & \multicolumn{2}{|c|}{$\begin{array}{c}\text { Group } 2 \\
(n=56)\end{array}$} & \multicolumn{2}{|c|}{$\begin{array}{c}\text { Group } 3 \\
(n=85)\end{array}$} & \multicolumn{2}{|c|}{$\begin{array}{c}\text { Group } 4 \\
(n=23)\end{array}$} \\
\hline & abs. & $\%$ & abs. & $\%$ & abs. & $\%$ & abs. & $\%$ \\
\hline Standard & 18 & 75 & 31 & 55.36 & 46 & 54.17 & 18 & 78.26 \\
\hline Pre-obesity & 3 & 12.5 & 18 & 32.14 & 25 & 29.41 & 5 & 21.74 \\
\hline Class I obesity & 2 & 8.33 & 4 & 7.14 & 7 & 8.24 & -- & -- \\
\hline Class II obesity & 1 & 4.17 & 1 & 1.78 & -- & -- & -- & -- \\
\hline Subnormal weight & -- & -- & 1 & 1.78 & 5 & 5.88 & -- & -- \\
\hline Underweight & -- & -- & 1 & 1.78 & 2 & 2.35 & -- & -- \\
\hline
\end{tabular}

Table 1: BMI in children with psoriasis.

Comparing the values exceeding the upper weight limits in children with psoriasis depending on the age, it was identified that the greatest increase in weight $(27.62$ $\pm 4.95 \%$ ) was observed in 4-7-year-old children (group 1 ), that was apparently different from the values of weight exceedance in children of group 2 and 4 (by $12.73 \pm 2.52 \%$ and $10.67 \pm 2.83 \%$ respectively, $\mathrm{p} \leq 0.05$ ).

The height of 96 children with psoriasis was ageappropriate, 59 (31.38\%) children were of above-average height, 24 (12.77\%) children were tall and 2-extremely tall. The combination of height and weight turned out to be very curious in children with increased BMI. The above-average weight and average height-the most typical combination for increased BMI - was reported in 24 children. The aboveaverage weight and height and the above-average weight combined with the mean height were observed in 18 and 12 children respectively. And even with the weight above average and extreme height 2 children had increased BMI (Table 2).

\begin{tabular}{|c|c|c|c|c|}
\hline Height Weight & Average & Above-average & Extremely high & Sub average \\
\hline Average & $2 / 62 / 3$ & $--/ 1 / 25$ & -- & $3 /---$ \\
\hline Above-average & $1 / 29 /--$ & $--/ 7 / \mathbf{1 8}$ & $--/--/ 1$ & $--/ 1 /--$ \\
\hline High & $2 / 3 /-$ & $--/ 5 / \mathbf{1 3}$ & $--/--/ 2$ & $--/-$ \\
\hline Extremely high & -- & $--/--/ 2$ & -- & -- \\
\hline Sub average & $--/ 5 /--$ & -- & -- & --1 \\
\hline Low & $--/--/ 1$ & & & \\
\hline
\end{tabular}

Table 2: Combination of weight and height in calculating BMI in children with psoriasis.

(BMI deficiency/ normal BMI/ increased BMI).

When assessing BMI in children of the control group (31) the following was identified: $61.29 \%$ of children (19) were identified to have normal body mass index, increased BMI was reported in 9 children (29.04\%) and 3 children were identified to have decreased BMI. Among the children with increased BMI pre-obesity was reported in 5 children, 3 were observed to have class I obesity and 1 child-class II. On average the exceedance of upper limits of the mean weight in children with increased BMI comprised $15.50 \pm 3.35 \%$ which has no significant difference between this group and group of children with psoriasis.

\section{Conclusion}

The research shows that among 188 children with psoriasis $35.11 \%$ of them were reported to have increased 


\section{Clinical Dermatology Open Access Journal}

BMI comparing to $29.04 \%$ of children of control group (OR, 1.23; 95\% confidence interval, 0.61-1.84). The largest number of children with increased BM-children aged $8-11 / 12(41.06 \%)$. Up to group 4 the gradual decrease in the number of children with increased BMI takes place, from $37.65 \%$ in group 3 to $21.73 \%$ in group 4 . The greatest increase in weight was observed in 4-7-year-old children with psoriasis: $27.62 \pm 4.95 \%$.

\section{References}

1. Habif TP (2016) Psoriasis and other papulosquamous diseases. Clin Dermatol, pp: 263-328.

2. Man MQ, Man G, Elias PM (2015) Could psoriasis be preventable? Dermatologica Sinica 33(4): 243-244.

3. Kumar B, Jain R, Sandhu K, Kaur I, Handa S, et al. (2004) Epidemiology of childhood psoriasis: a study of 419 patients from northern India. Int J Dermatol 43(9): 654658.

4. Raychaudhuri SP, Gross J (2000) A comparative study of pediatric onset psoriasis with adult onset psoriasis. Pediatr Dermatol 17(3): 174-178.

5. Sommer R, Mrowietz U, Radtke MA, Schafer I, von Kiedrowski R, et al. (2018) What is psoriasis?- Perception andassessment of psoriasis among the German population. J Dtsch Dermatol Ges 16(6): 703-710.

6. Ozden MG, Tekin NS, Gurer MA, Akdemir D, Dogramaci C, et al. (2011) Environmental risk factors in pediatric psoriasis: a multicenter case-control study. Pediatr Dermatol 28(3): 306-312.

7. Paller AS, Mercy K, Kwasny MJ, Choon SE, Cordoro KM, et al. (2013) Association of pediatric psoriasis severity with excess and central adiposity: an international cross-sectional study. JAMA Dermatol 149(2): 166-176.

8. Becker L, Tom WL, Eshagh K, Benjamin LT, Paller AS (2014) Excess adiposity preceding pediatric psoriasis. JAMA Dermatol 150(5): 573-574.

9. Naldi L, Peli L, Parazzini F, Carrel CF (2001) Psoriasis Study Group of the Italian Group for Epidemiological Research in Dermatology. Family history of psoriasis, stressful life events, and recent infectious disease are risk factors for a first episode of acute guttate psoriasis: results of a case-control study. J Am Acad Dermatol 44(3): 433-438.

10. Telfer NR, Chalmers RJ, Whale K, Colman G (1992) The role of streptococcal infection in the initiation of guttate psoriasis. Arch Dermatol 128(1): 39-42.

11. Yoon S, Oh ST, Lee JY, Cho BK (2007) Plaque type psoriasiform eruption following Kawasaki disease. Pediatr Dermatol 24(3): 336-337.

12. Liao YC, Lee JY (2009) Psoriasis in a 3-month-old infant with Kawasaki disease. Dermatol Online J 15(11): 10.

13. Haddock ES, Calame A, Shimizu C, Tremoulet AH, Burns JC, et al. (2016) Psoriasiform eruptions during Kawasaki disease (KD): a distinct phenotype. J Am Acad Dermatol 75(1): 69-76.

14. Cullen G, Kroshinsky D, Cheifetz AS, Korzenik JR (2011) Psoriasis associated with anti-tumour necrosis factor therapy in inflammatory bowel disease: a new series and a review of 120 cases from the literature. Aliment Pharmacol Ther 34(11-12): 1318-1327.

15. Perman MJ, Lovell DJ, Denson LA, Farrell MK, Lucky AW (2012) Five cases of anti-tumor necrosis factor alpha-induced psoriasis presenting with severe scalp involvement in children. Pediatr Dermatol 29(4): 454459.

16. Eickstaedt JB, Killpack L, Tung J, Davis D, Hand JL, et al. (2017) Psoriasis and psoriasiform eruptions in pediatric patients with inflammatory bowel disease treated with anti-tumor necrosis factor alpha agents. Pediatr Dermatol 34(3): 253-260.

17. Takeshita J, Grewal S, Langan SM, Mehta NN, Ogdie A, et al. (2017) Psoriasis and comorbid diseases: epidemiology. J Am Acad Dermatol 76(3): 377-390.

18. WHO (2020) Obesity and overweight. Fact Sheet, World Health Organization.

19. IARC (2002) In: Weight Control and Physican Activity. International Agency for Research on Cancer. $6^{\text {th }}$ (Vol), Lyon, France.

20. Must A, Spadano J, Coakley EH, Field AE, Colditz G, et al. (1999) The disease burden associated with overweight and obesity. JAMA 282(16): 1523-1529.

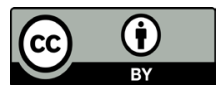

